\title{
Free Time, Freedom, and Fairness ${ }^{1}$
}

\author{
JEPPE VON PLATZ \\ University of Richmond
}

\begin{abstract}
Julie Rose argues that free time is a proper concern of distributive justice and that all citizens have a legitimate claim to a fair share of free time. Her argument relies on the effective freedoms principle, which says that all citizens have a legitimate claim to a fair share of the resources required to exercise their formal liberties and opportunities. Rose argues that free time is one such resource, which entails that all citizens have a legitimate claim to a fair share of free time. I argue that Rose's argument does not establish a claim to a fair share of free time, at least not if we understand fairness to mean something more than that all should receive their due. I also suggest an extension of Rose's argument that yields the conclusion that all citizens have a legitimate claim to a cooperatively fair share of free time.
\end{abstract}

Keywords: time, justice, freedom, rights, fairness, work

"In capitalist society, free time is produced for one class by the conversion of the whole lifetime of the masses into labourtime." (Marx 1976: 667)

\section{INTRODUCTION}

In Free Time, Julie Rose argues that "justice requires that all citizens have a fair share of free time" (2016: 4; see also 1, 5, 17, 63, 68, 73, 85, 92, 128). Rose defines free time as "time beyond that which is objectively necessary for one to spend on one's own basic needs, or the basic needs of one's dependents" (2016: 58). Accordingly, justice requires that all citizens have a fair share of time to spend on pursuits other than these basic needs. This thesis might appear uncontroversial, but, as Rose notes (2016: 1, 3, 17-18, 90), most contemporary theories of justice do not include any principles concerning the distribution of free time. Moreover, if sound, her argument

1 I am grateful to Tom Parr, two anonymous reviewers, and Lauren McGillicuddy for helpful written comments on an earlier version of this essay. 
warrants a complaint of justice against most societies, for few societies seem to secure a fair share of free time for all.

Rose's argument starts with the effective freedoms principle, which Rose states as follows (2016: 66-7; see also 4, 73, 74, 101, 111, 128-30): "citizens have legitimate claims to a fair share of the resources generally required to exercise their formal liberties and opportunities". Rose takes this principle as a given, since it is endorsed by "nearly all theories of distributive justice" (2016: 66; also 90). Liberals tend to use this principle to defend conclusions about material conditions, but Rose argues (2016: chapters 3 and 4) that free time is generally required to exercise formalliberties and opportunities. To illustrate, think of the political rights of democratic citizenship: rights to form, join, and leave political parties, to voice one's opinion in political matters, to participate in elections, and so on. Exercising these rights takes time - time to discern the nature of political questions, the positions of the candidates, what justice and efficiency requires, and to vote on election days (Rose 2016: 73-74). In general, it takes time to exercise many of the formal liberties that liberals argue all citizens should enjoy; so, by the effective freedoms principle, justice requires that all have a fair share of free time. Here is the argument in overview:

1. All citizens have a legitimate claim to a fair share of the resources generallyrequired to exercise theirformalliberties and opportunities. (= The effective freedoms principle.).

2. Free time is a resource generally required to exercise one's formal liberties and opportunities.

3. Therefore, all citizens have a legitimate claim to a fair share of free time.

Rose's argument offers an important corrective to a theoretical neglect of a real and practical dispute. Free time is a subject of justice; it has been neglected by political philosophy, and all citizens have a claim to free time. Moreover, since time has played a central role in the struggle between capital and labor, the theoretical neglect of free time, and time more generally, is remarkable. The history of the working class is as much a history of the struggle for time - for shorter and reasonably organized work-weeks, pay for overtime, lunchbreaks, sick-days, holidays, vacation, varieties of paid and unpaid leaves - as for fair wages and workplace safety. ${ }^{2}$ This struggle for time continues.

However, I have some concerns about Rose's argument. Rose relies on the

2 For example, the 1891 Erfurt Program of the German Social Democratic Party demands an eight-hour workday, limitations on night-work, and uninterrupted rest periods of at least 36 hours once per week (e.g. Sundays off work). 
effective freedoms principle to establish the conclusion that all citizens have a legitimate claim to $a$ fair share of free time. But I doubt that the effective freedoms principle can get her this conclusion, at least not if we understand "fair share" in terms of cooperative fairness.

I also worry that Rose's reliance on the effective freedoms principle leads her to miss an opportunity for thinking about free time as an issue of justice which is theoretically appealing, true to the historical (and continuing) struggles for time, and can support the sort of claims to a cooperatively fair share of free time that the effective freedoms principle does not deliver.

My argument begins with a few distinctions. First, I distinguish between two parts of economic justice, which I call enabling and distributive justice. The former requires that all citizens are enabled to participate as free and equal in social cooperation, the latter that the distribution of the benefits and burdens of cooperation is fair. Second, there is the already indicated ambiguity in the notion of fairness. Fairness can be understood as the somewhat vacuous requirement that the resources useful for pursuing conceptions of the good in general (so-called all-purpose means) should be fairly distributed. But it can also be understood in terms of the more specific notion of cooperative fairness, where it says that cooperators have a claim to receive a fair share of the benefits, and to carry only a fair share of the burdens, of their cooperation.

Third, there is an ambiguity in the effective freedoms principle which leads to two different arguments that free time is a concern of economic justice. Free time is of concern to justice, both because free time is necessary for exercising basic liberties and because free time is an all-purpose means. ${ }^{3}$ This duality is mirrored in two different readings of the effective freedoms principle and these, in turn, issue different requirement of justice with respect to free time. On one reading, the effective freedoms principle is tied to the basic liberties. On another reading, the effective freedoms principle is tied to the ability to freely pursue one's interests. Rose does not have to choose between these meanings, for she shows that free time is a resource in both senses. However, I argue that the effective freedoms principle is best understood as tied to basic liberties, and that, thus understood, the claims of justice it supports are not claims to fair shares of free time, but rather sufficientarian claims to adequate amounts of free time.

The indicated ambiguities are not particular to Rose's argument, nor do they by themselves produce fallacies or nasty dilemmas. But resolving them

3 “ $[\mathrm{F}]$ ree time is required both to exercise many of one's fundamental freedoms and to pursue one's con-ception of the good, whatever it may be" (Rose 2016: 71). 
will, I hope, bring more clarity to the (in my opinion, limited) purchase of the effective freedoms principle. It will also allow me to suggest a way to extend Rose's argument so that it supports the conclusion that all citizens have a claim to a cooperatively fair share of free time.

\section{ECONOMIC JUSTICE: ENABLING AND DISTRIBUTIVE}

If we accept the Rawlsian idea that we should think about the principles of economic justice as the basic rules of cooperation between free and equal citizens, the principles of justice can then be applied to draw distinctions between different resources (or primary goods) according to how they are related to the social cooperation governed by these principles. In the Rawlsian framework, these all-purpose means include basic liberties, opportunities, wealth and income, and the social bases of self-respect. Some of these resources (the basic liberties and the resources required to exercise them) are of interest to economic justice because they enable citizens to participate as free and equal in the system of social cooperation. Other resources are of interest to ensure the ongoing fairness of the distribution of opportunities to pursue one's goals, benefits, and burdens of cooperation.

The general notion of all-purpose means can thus be disaggregated into three ways in which resources are of interest to economic justice:

First, as basic rights and liberties necessary for citizens to develop and exercise the moral powers engaged in social cooperation.

Second, as the material (and temporal) background conditions for citizens to actually enjoy these rights and liberties to the sufficient degree.

Third, as the inputs and outputs (burdens and benefits) of the productive and distributive processes of social cooperation.

Of course, the same resource can appear in multiple categories. Thus, wealth will appear both as the second and third sorts of resource, since some wealth is necessary to exercise one's basic rights and wealth is an output of social cooperation.

This way of thinking about how resources are significant for justice also indicates a division of the subject of economic justice - a division that I believe is general to those liberal egalitarian theories of justice that should share Rose's commitments, and which turn out to be helpful for my discussion of her argument. This is the division between the enabling and 
the distributive parts of economic justice. ${ }^{4}$

Enabling justice is concerned with empowering all citizens to be free and equal participants in social cooperation. Distributive justice is about how we should distribute the burdens and benefits of social cooperation taking place among citizens thus empowered. Enabling justice requires that all members have access to the rights and means sufficient to participate in social cooperation as free and equal. Distributive justice requires that citizens carry at most a fair share of the burdens and receive at least a fair share of the benefits of social cooperation. In terms of the three kinds of resources identified above, we can say that enabling justice is concerned with the first two kinds; distributive justice with the third kind. In Rawls's theory of justice, the first principle of justice expresses the requirements of enabling justice, the second principle expresses the requirements of distributive justice. Enabling justice is sufficientarian. The aim is to ensure that all citizens are empowered to cooperate, which means they should all enjoy access to the basic liberties and the means sufficient to exercise these. Distributive justice could be, but typically is not sufficientarian, for the claims it supports are to fair relative shares of burdens and benefits.

\section{TWO NOTIONS OF FAIRNESS}

The general requirement of economic justice is that we should seek a just (we might say, fair) distribution of all-purpose means. Rose shows that free time is an all-purpose means and so should be fairly distributed. However, notice that little is revealed by saying that these resources should be fairly distributed. This general notion of fairness says little more than that these resources are proper subjects of economic justice, so that all should receive their due of these. It is the role of the principles of economic justice to specify what a fair distribution of these resources would look like.

We find a more interesting notion of fairness when it is defined in terms of cooperation, so that the basic norm is that the rules that govern cooperation must secure each cooperator's claim to a fair share of the benefits and burdens of their cooperation. To be clear, here are the two notions of fairness: ${ }^{5}$

4 These two parts do not exhaust the subject of justice, but they are the main parts of what I call economic justice, that is, the principles that should guide the design of institutions that define and regulate social cooperation.

5 There are, of course, many others. 
Non-cooperative fairness: we can talk about fairness as the general notion governing the distribution of all-purpose means in general. The norm is that all-purpose means should be fairly distributed.

Cooperative fairness: we can talk about fairness in terms of the claims of cooperators to the benefits and burdens of their cooperation. Here the norm is that all cooperators receive at least a fair share of the benefits, and carry no more than a fair share of the burdens, of cooperation.

The distinction applies in other contexts as well. If we are served with a pie, then all should receive their fair share of it (non-cooperative fairness). If we bake the pie together, each has a claim to a fair share of it (cooperative fairness). But the distinction has particular relevance for economic justice, for theories of economic justice can be divided into those that theorize economic justice in terms of cooperative fairness and those that do not.

The non-cooperative notion of fairness is pre-theoretical and vacuous. To say that justice requires that all receive their fair share in this sense is to say that all should receive their due - a statement that, if not analytical, is so generic that any and all theories of justice could include it. Libertarians, classical liberals, socialists, Rawlsians, and social democrats could all agree to this principle, while disagreeing about what it means.

The cooperative notion of fairness is the general norm of what I called distributive justice above. It presents us with a stronger and more interesting notion of fairness. One indication of its relative strength is that right-liberal and libertarian theories of justice would not accept it as norm of economic justice, since they reject the idea that we should think of society as a system of social cooperation (e.g. Hayek 1978; Nozick 1974: chapter 7). And it is more interesting, since the notion ties fairness directly to the claims that cooperators can make on each other as cooperators, which invites more demanding norms of reciprocity and the idea that departures from an equal distribution must be reasonably acceptable to those who have less (since all come into the cooperative relationship as free and equal and thus with an initially equal claim to the benefits and burdens of cooperation).

To further illustrate the distinction, it might be helpful to think again in terms of Rawls's theory of justice. The general question is what a fair distribution of all-purpose means would look like (using the noncooperative notion of fairness). The two principles of justice answer this question. However, this answer involves the cooperative notion of fairness, namely the claim to a fair share of benefits and burdens that each cooperator has as cooperator. While this cooperative notion of fairness is 
more specific in terms of content than the first, it also needs further specification. In Rawls's theory this further specificity is provided by the second principle of justice. Other theories might offer different principles to specify cooperative fairness, but the notion itself restricts the domain of available answers.

With this distinction in mind, we can see that Rose's conclusion that all citizens have a claim to a fair share of free time is ambiguous between the weaker conclusion that free time should be fairly distributed where fairness is used in the non-cooperative, untheorized, and less demanding sense; and the stronger conclusion that free time is subject to the norms of cooperative fairness. In the following two sections I argue that Rose's arguments from the effective freedoms principle can support only the weaker of these two conclusions. In section 5 I sketch an argument that leads to the stronger conclusion.

\section{TWO READINGS OF THE EFFECTIVE FREEDOMS PRINCIPLE}

Corresponding to the two senses in which free time is a resource, we can distinguish between two readings of the effective freedoms principle:

General liberty reading: All citizens should receive a fair share of all-purpose means useful for freely pursuing their conception of the good, whatever it may be.

Basic liberties reading: All citizens have a legitimate claim to the resources adequate to exercise their basic liberties.

Both of these are at work in Rose's argument; the first, when she treats free time as an all-purpose means; the second, when she treats it as required for the exercise of basic liberties.

It seems clear that the first reading of the effective freedoms principle simply restates the general requirement of non-cooperative fairness that all-purpose means should be fairly distributed, which means that nearly all theories of justice can include it.

The second reading of the principle has more bite, and it seems that right-liberals and libertarians would reject it. This need not concern Rose, for the principle has a secure place in any liberal egalitarian theory of justice of the sort which Rose argues should concur with her conclusions. Rose shows that free time is necessary for various basic liberties, including freedom of occupation, basic political rights, and freedom of association (2016: 91, 73-4, chapter 5). These arguments successfully establish that all citizens have a claim to the sufficient measure of free time required to exercise these liberties. 
Though Rose uses both readings of the effective freedoms principle, this is a strength of her argument, rather than a problem, for it shows that free time is a subject of justice in two distinct senses: in general, as an allpurpose means, and in particular, as a condition of the exercise of basic liberties. The problem, rather, is that neither of these senses supports the stronger conclusion that free time is a subject of cooperative fairness, which means that her conclusion - that all citizens have a claim to a fair share of free time - is true only if we take fairness in the non-cooperative and vacuous sense. At least, so I argue in the following section.

\section{FREE TIME AS SUBJECT OF ENABLING JUSTICE}

To give some substance to my worry, it will be helpful to look at the place of the effective freedoms principle in Rawls's theory of justice. ${ }^{6}$ Looking at Rawls also offers further explanation for why enabling justice is sufficientarian.

Rawls repeatedly says that something like the effective freedoms principle defines membership in the family of liberal theories of justice. Rawls defines liberalism as those theories of justice that affirm the basic rights and liberties familiar from liberal democratic regimes, give special priority to these rights and liberties, and secure for all citizens "adequate all-purpose means to make effective use of theirliberties and opportunities" (1996: 6; see also lix; Rawls 2008: 12; Rawls 2001: 141). In this sense he affirms the effective freedoms principle. Yet the effective freedoms principle is not a distinct principle alongside the two principles of justice as fairness, and Rawls appears to think it is covered by what he says with respect to the enabling conditions of the first principle of justice, the principle of equal basic liberties.

The first principle itself does not affirm or contain the effective freedoms principle, but in Political Liberalism, Rawls writes that the first principle should be understood as working within a setting where citizens' basic needs are met, "at least insofar as their being met is necessary for citizens to be able to understand and to be able to fruitfully exercise those rights and liberties" (1996: 7). Thus, Rawls employs the effective freedoms principle in the second, basic liberties reading identified above. And as such, the principle issues the sufficientarian requirement that basic needs are met, where needs are understood as the preconditions for exercising the basic rights and liberties. Accordingly, it is not the case that citizens have a legitimate claim to a fair share of the resources required for principle.

6 Rose (2016: 67, 70) mentions Rawls as exemplary endorser of the effective freedoms 
exercising their basic liberties; rather, they have a legitimate claim to the amount of those resources adequate to exercise their basic liberties. By the distinction drawn earlier, the effective freedoms principle thus serves as a principle of enabling rather than of distributive justice.

The role of the effective freedoms principle in Rawls's theory illustrates how it serves as a principle of enabling justice, and can be satisfied whether or not citizens receive a cooperatively fair share of resources. As a principle of enabling justice, the principle carries a target and cutoff point for the resources it covers - once all citizens have enough of those resources to exercise their basic liberties, it issues no further requirements.

To summarize, once we have the distinction between enabling and distributive justice in hand, and once we have distinguished between noncooperative and cooperative fairness, and once we have clarified the two readings of the effective freedoms principle, we can say that:

First, if we use the general liberty reading of the effective freedoms principle, then the principle says little more than that all-purpose means should be fairly distributed, where fairness is used in the non-cooperative, pre-theoretical, vacuous sense. In this employment, the effective freedoms principle does support the conclusion that free time should be fairly distributed, but not in the strong sense of cooperative fairness.

Second, if we use the basic liberty reading of the effective freedoms principle, then the principle is a principle of enabling justice. As such, it issues strong requirements of justice with respect to free time, namely, that all must enjoy access to free time sufficient to enjoy their basic liberties. However, this requirement does not support claims to fair shares, merely to adequate amounts.

So, third, neither of the two readings of the effective freedoms principle can be used to establish the conclusion that the distribution of free time is a subject of the cooperative norms of fairness of distributive justice.

So, fourth, Rose's argument has not established that all citizens have a claim to a fair share of free time, if we understand fairness in the stronger sense of cooperative fairness.

Rose's main conclusion that free time is a subject of justice stands untouched by my argument. Indeed, she has shown that the distribution of free time should be fair, if we understand fairness in the general, pre-theoretical, non-cooperative sense that people should receive their due share of free time. Moreover, as Rose makes clear (2016: 128-3), she 
does not claim that her argument determines which principle should govern the distribution of free time, so she can leave that matter to be settled by the various theories of justice in light of their respective interpretations of fairness.

However, by relying on the effective freedoms principle, Rose's argument misses an opportunity for developing free time as a subject of what I have called distributive justice and thus as subject to the stronger norms of cooperative fairness. In the following section I offer a suggestion to extend Rose's argument and make free time a subject of norms of cooperative fairness; thereby offering a way to reach the conclusion that all citizens have a legitimate claim to a fair share of free time, in the stronger, cooperative sense of a fair share.

However, first, I want to acknowledge two complications that deserve mention, though they do not change my conclusion. First, even as subjects of enabling justice, some resources are rivalrous goods: the amount of them needed to exercise a basic liberty depends on what others have. This makes it harder to determine what the adequate amount is, but it does not change the nature of the claim, which is to an adequate amount; thus, there is a threshold at which the claim of enabling justice to that resource is fully satisfied (even if this threshold varies with what others have). This point generalizes to other sufficientarian claims of justice; even if the resource covered by the sufficientarian guarantee is a rivalrous good, the nature of the claim still has the sufficientarian characteristics of adequacy, cutoff-points, and non-relativity (even if the absolute amount one has a claim to is a function of what others have, it is still not a claim to a relative share, but to enough to pass the threshold, which may depend on what others have).

The second complication is that some (if not most) resources are subjects of both enabling and distributive justice. Again, take money as an example. On one hand, money is needed to exercise basic liberties, so all citizens have a legitimate claim of enabling justice to enough income and wealth to exercise their basic liberties. On the other hand, money serves as both an input and an output of the system of cooperation (and translates smoothly into many of the benefits and burdens of cooperation), so the distribution of income and wealth also is a proper subject of distributive justice, meaning that all citizens have a legitimate claim to a cooperatively fair share of income and wealth. Below, we shall see that free time also is a subject of justice in both senses. 


\section{FREE TIME AS A SUBJECT OF DISTRIBUTIVE JUSTICE}

It is, I think, hard for an argument that relies on the effective freedoms principle to deliver norms of cooperative fairness. Here I suggest a way in which Rose's argument could be extended to distributive justice and issue the more demanding norms of cooperative fairness that rule that domain. For I do think that time and free time are proper subjects also of distributive (rather than only enabling) justice, and that norms of cooperative fairness apply to the distribution of free time. But to see this, we have to think outside the scope of the effective freedoms principle.

Let us return to time and free time as resources. As Rose identifies it (2016: 46), a resource that could plausibly be the subject of a claim of justice must be "generally required to pursue any conception of the good," and it must be practically possible to know and verify whether individuals possess the resource. I suggested earlier that this general notion can be disaggregated into three sorts of resources: basic liberties, the means needed to exercise these to the sufficient degree, and the inputs and outputs of social cooperation. The basic liberties reading of the effective freedoms principle deals with the second of these; norms of cooperative fairness deal with the third. Rose shows that free time is an all-purpose means required for the exercise of basic liberties. I argue that free time is also a resource in the third sense, which makes it subject to the norms of cooperative fairness.

Why do we have social cooperation in the first place? One straightforward answer is that through social cooperation we get better access to all the good things of life: security, transportation, comfortable shelter, food, potablefluids, peace, freedom, stability, the pursuit and dissemination of knowledge, cultural enrichments, innovation and the development of technologies, health-care, comforts in old age; the list goes on and on. A host of things that human beings care about are available only in society and through social cooperation. There are, of course, inputs and outputs to the processes by which these many goods and advantages are produced and distributed: resources are both consumed and created by these processes. One way to think about distributive justice (the right way, I think) is that we need principles to guide the distribution of both inputs and outputs - the sharing of the burdens and benefits of social cooperation.

Time is one of the inputs to this process of social cooperation, and free time is one of the outputs. Even with every advance of modern technology, what we produce requires the investment of time alongside other inputs such as natural resources and knowledge. The time thus spent is work (in a 
broad sense); burdensome, but productive. ${ }^{7}$ (This expands the concept of work to include currently uncompensated care-work and uncompensated artistic endeavors that truly enrich society). For in exchange for the collective time spent working, we get not only all the good products of our work, but our collective work also frees up time itself - the division of labor and the productive nature of social cooperation and the progress that we make when we cooperate all make it so that we do not have to work every waking hour to satisfy our basic needs or the basic needs of our dependents. (Some still do, and if they must, maybe that is unjust for the reasons Rose lists, and because they do not receive a cooperatively fair share of free time). If we didn't live in society and cooperate, we would spend nearly all our time trying to survive; living in society, we sometimes are released from the imperatives of basic needs and have time to do what we want. Free time is, of course, intangible and usually not traded as a separate commodity, but the same could be said for the other main social goods: freedom, security, and access to knowledge and cultural enrichments.

The norms of cooperative fairness say that the distribution of the benefits and burdens of social cooperation should be distributed in a manner that is fair to all cooperating parties. Since time is a factor of production and free time one of the products, it follows that all cooperating citizens have a claim to contribute no more than their fair share of time, that is, to work no more than their fair part, and to receive no less than their fair share of free time. They can, of course, choose to keep working in their free time, insofar as they want to exchange their free-time resource for other resources.

It is hard to say much more in the abstract about what cooperatively fair shares of benefits and burdens are. But we can say that time and free time are proper subjects of distributive justice and the norms of cooperative fairness appropriate to it. And that, in turn, allows us to say that the requirements of justice with respect to time are open-ended rather than sufficientarian (there is no target and cutoff point), that inequalities of free time need justification, that relative shares of free time matter, that the struggle for a fair distribution of work time and free time continues beyond the point where all citizens have enough time to exercise their basic liberties, and that it looks like a problem of justice when some must work a lot and others work little; when some have just enough free time, while others can choose a life of leisure. If Marx was right (cf. opening quote), the problem is not merely that the working class has insufficient free time, but

7 Of course, not all work is equally burdensome and perhaps some work is not burdensome at all. But for the purposes of distributive justice, it makes sense to assume, so that sentence reads "it makes sense to assume that work is normally burdensome." 
that a capitalist society tends to suffer from an unfair distribution of work time and free time.

Thus, time is a subject of justice in two ways and citizens have at least two distinct claims of justice when it comes to free time. First, as Rose persuasively argues, free time is a subject of enabling justice. As such, free time is covered by the effective freedoms principle and all citizens have a claim to an amount of free time sufficient to exercise their basic rights. Second, as sketched in this section, work time and free time are subjects of the norms of cooperative fairness that govern distributive justice. As such, all citizens have a claim to use no more than a fair share of time at work, and to receive no less than their fair share of free time in return for their work.

The history of the working class struggle for time is based on both of these claims of justice. But I believe that in capitalist economies, the tendency is for the capitalists to receive more than their fair share of free time, and to provide less than their fair share of time as a factor of production. The leisure class have their good times at the expense of the hard times of the working class. And that is unfair, not because the working classes do not have enough time to exercise their basic liberties - if that is the case, it is unjust in another sense - but because this exhibits an unfair distribution of the burdens and benefits of cooperation. When the working classes keep fighting for shorter and more reasonably structured work weeks, paid vacation, and so on, they have not and need not couch their demands in terms of basic needs, for they can make their claims in terms of cooperative fairness; of carrying only their fair share of the burden and receiving their fair share of the benefits of the productive processes of society. By contrast with claims based on the effective freedoms principle (or similar principles of enabling justice), cooperative fairness justifies claims to fair shares on an ongoing basis even after all basic needs have been met. The struggle between capital and labor does not end once basic needs are met (or the effective freedoms principle is satisfied); the struggle for fairness remains.

\section{CONCLUSION}

Rose argues that the effective freedoms principle supports a claim for all citizens to a fair share of free time. I have argued that the effective freedoms principle is ambiguous between two readings, each of which supports a distinct argument with respect to free time. On the first reading, the effective freedoms principle restates the general idea that all-purpose means should be fairly distributed. Since free time is such an all-purpose means, it should be fairly distributed. On the second reading the principle 
requires that all citizens have access to the resources required to exercise their basic liberties. Since some measure of free time is required to exercise basic liberties, all citizens should enjoy access to this measure of free time.

Both arguments are sound; Rose has successfully established that free time is a proper subject of justice. However, neither of the arguments establishes that all citizens have a legitimate claim to a fair share of free time - at least not if we understand fairness in the stronger sense of cooperative fairness. For the first argument establishes that all citizens should receive a fair share, but employs the general, non-cooperative, and vacuous notion of fairness. The second argument does not establish a claim to a fair share, but a claim to the amount adequate to exercise the basic liberties.

I also suggested a way in which Rose's argument can be extended to establish the stronger conclusion that free time is a subject of cooperative fairness, though to do so we have move beyond the effective freedoms principle. For, I argued, time and free time are real concerns of distributive (as opposed to enabling) justice, and as such are subjects of norms of cooperative fairness. Time spent working is one of the inputs and burdens of the cooperative processes by which we create the social goods, and free time is one of the outputs and benefits made available through social cooperation. Thus, all citizens have a claim to contribute no more than a fair share of their time in the form of work, and to receive no less than a fair share of free time. These requirements of distributive justice are not sufficientarian, have no target or cut-off point of adequacy, and thus support claims to a just distribution of work time and free time beyond the point where all have sufficient free time to exercise their basic liberties.

When it comes to time as a concern of justice, I believe this concern with time as a subject of cooperative fairness is as important as the concerns Rose establishes. Moreover, I'm inclined to think that this concern for time as a subject of cooperative fairness is needed to make sense of the ongoing struggles over time between labor and capital. That struggle will not and should not end once citizens have enough free time to exercise their basic rights, for an adequate amount for all is consistent with distributive injustice

\section{BIBLIOGRAPHY}

Hayek, F.A.v., 1978: Law, Legislation, and Liberty, Volume 2: The Mirage of Social Justice, Chica-go: Chicago University Press.

Marx, K., 1976 [1867]: Capital: Critique of Political Economy, Volume 1, London, UK: Penguin Classics. 
Nozick, R., 1974: Anarchy, State, and Utopia, New York, NY: Basic Books.

Rawls, J., 1999: A Theory ofJustice, Revised Edition, Cambridge, MA: Harvard University Press.

-2005: Political Liberalism - Expanded Edition, New York: Columbia University Press.

-2001: The Law of Peoples: with “The Idea of Public Reason Revisited", Cambridge, MA: Harvard University Press.

-2008: Lectures on the History of Political Philosophy, ed. S. Freeman, Cambridge, MA: Harvard University Press.

Rose, J., 2016: Free Time, Princeton: Princeton University Press. 